These data shows that small service developments can make a big impact on palliative patients and the opportunity to exercise can and should be made available to all patients.

\section{P-105 ENGAGING PEOPLE TO EMPOWER PATIENTS}

${ }^{1,2}$ Karen Clarke. 'St Wilfrid's Hospice, Eastbourne, UK; ' Lancaster University, Lancaster, UK

\subsection{6/bmjspcare-2016-001245.128}

Background Despite having a life-limiting illness, patients wish to remain as independent as possible during their disease course (Yoshioka, 1994) and if this is optimised it can ameliorate their perceptions of hopelessness and despair and relieve some of the burden on the caregiver. Although intended to be supportive, evidence suggests that hospice palliative care may disable patients and reduce their ability to do things for themselves (Jennings, 2012).

Aims Explore how an approach to palliative care that focuses on maximising functional status, physical independence and quality of life, whilst acknowledging the patient's advanced disease and limited life span, can be integrated into a hospice in-patient setting.

Methods The setting is a 15 -bedded hospice inpatient unit.

Using participatory action research, a co-operative inquiry group (CIG) of clinical and non-clinical staff and volunteers collectively developed their knowledge in relation to a rehabilitative approach and organisational change; planned how to integrate a rehabilitative focus into the in-patient setting, attending to the potential facilitators and barriers; led on the agreed actions; met regularly to review progress and agree how the study should be evaluated.

Following the situational analysis, the CIG planned what action to take and after each period of activity, assessed the outcome and then further action was planned and executed.

Organisational change theory provides the theoretical lens for the study.

Results Achievements to date are aligned with Kotter's (2014) leading change model as follows:

- the CIG are excited and committed to change within the organisation, and

- have become the guiding coalition for the change process

- a vision is emerging to steer the change.

Conclusions Data collection will continue until June 2016 but early indications suggest that a group of hospice staff and volunteers identifying, owning and acting collaboratively, as described by Pascale and Sternin's (2005) positive deviance model, can form the basis of effective organisational change.

\section{P-106 THE POTENTIAL WITHIN US - SELF-MANAGEMENT THROUGH EXERCISE: A PHASED APPROACH TO RESEARCH}

\footnotetext{
${ }^{1}$ Abby McCarthy, ${ }^{2}$ Barbara Miller, ${ }^{2}$ Suzy Hudson, ${ }^{3}$ Sarah Klinger, ${ }^{4}$ Katie Margetts, 2,3 Karenann Spicer, ${ }^{5}$ Jo Clark, ${ }^{3}$ Trudy Leighton. ${ }^{1}$ Garden House Hospice, Letchworth, UK; ${ }^{2}$ The Hospice of St Francis; ${ }^{3}$ Peace Hospice Care; ${ }^{4}$ Isabel Hospice; ${ }^{5}$ Rennie Grove Hospice Care

10.1136/bmjspcare-2016-001245.129
}

Rehabilitative palliative care is a developing field integrating rehabilitation, enablement, self-management and self-care into the holistic model of palliative care. A growing evidence-base suggests that rehabilitation not only delays or prevents deterioration in function but can actively improve physical function irrespective of advance disease. The drive towards rehabilitative palliative care has led to an increase in the application of self-management techniques within hospices but there appears to be a gap in the empirical evidence specific to palliative care.

The challenges, possible solutions and anticipated patient benefits of hospices being research active have also been highlighted.

In response, palliative care professionals across five hospices formed a collaborative group and planned a phased approach to research.

Phase 1: A literature review (March - May 2016) to establish the evidence-base for self-management in palliative care. This identified a significant gap in evidencing the outcomes of selfmanagement in the palliative population.

Phase 2: A collaborative service evaluation (April - May, 2016) identifying self-management opportunities for patients within the hospices followed by a patient survey on the exercise groups they attended.

This suggested that promoting self-management through exercise was both acceptable and beneficial in a palliative population. Patient responses showed exercise:

- Enabled patients to cope better with their illness

- Increased their confidence in maintaining/improving activity levels

- Provided a focus for independent goal setting

- Facilitated independent activity outside of the organisation.

Phase 3: The work is being written up for publication to contribute to the evidence-base supporting the beneficial effects of self-management through exercise and the potential this has to improve patients' quality of life.

Phase 4: Moving forward the group aims to seek funding to extend this work into a research project and ultimately to drive further research through a dedicated research post.

\section{P-107 THE BE IN CHARGE PROGRAMME - SUPPORTS PATIENTS TO TAKE MORE CONTROL THEIR OWN CARE IN ORDER TO GET ON WITH THEIR LIFE}

Yvonne Cochrane, Denise Richards. Teesside Hospice, Middlesbrough, UK

\subsection{6/bmjspcare-2016-001245.130}

Background With the recognition of the growing number of people living longer with cancer and other life-limiting illness the hospice have undertaken a review of the service we offer.

Through a series of focus groups with patients and professionals from hospital and community teams it was evident that there was a need for a different kind of support for some patients. Therefore a new hospice service a six-week programme called the 'Be in Charge' programme was introduced.

Aim

- To help patients cope better with the symptoms of their illness and take more control in their own care

- To provide a space to talk and share experiences with other patients in similar situations

- To have an opportunity to learn coping skills to manage symptoms and the difficulties they may be experiencing

- The opportunity to have an introduction to the hospice and the services offered as well as identity a need for a different level of support 
Method This new programme does involve sessions to teach patients coping skills and is delivered by a multiprofessional team skilled in supporting patients with complex needs. Each week includes an exercise session and an opportunity to try several forms of relaxation. The programme is supported throughout with a cognitive behavioural therapies approach.

Results All patients are given a patient questionnaire as well as completing a Holistic Assessment of Needs Tool, an outcome measure completed prior to the group and afterwards to establish what benefit the group had made to patients' needs.

Pre and post exercise tolerance tests and evaluations are used. Conclusion Overall the results are extremely positive identifying that the 'Be in Charge' group was a real success. Therefore with the support from the hospice board of trustees we have now gained funding in order to deliver six programmes a year.

\section{P-108 EXERCISE IN PALLIATIVE CARE, GOING THE EXTRA MILE}

Emily Whiteoak. Hospice Care for Burnley and Pendle (Pendleside Hospice), UK

\subsection{6/bmjspcare-2016-001245.131}

Patients with life-limiting illnesses often experience functional impairment, resulting in poorer quality of life. Studies have shown that exercise can improve physical, emotional and psychological wellbeing, which all help maintain independence: Findings highlight that exercise in palliative care should not be viewed solely a physical intervention, but one that has potential to enhance many aspects of patients' quality of life (Turner et al., 2016)

As part of our rehabilitation service we aim to develop the exercise therapy element to meet the needs of the individual. We offer tailor made exercise programmes to achieve the best possible outcome for the patient.

The disease status or location of the individual patient is not a barrier to our service.

For example the rehabilitation assistant initially sees a patient in the outpatient setting. As disease progresses and status reduces the same patient maybe offered a different approach in the most appropriate setting.

This maybe

- Home

- Inpatient unit

- Day service unit

- Outpatients

- Group sessions

- $1: 1$.

It is acknowledged that the exercise therapy we deliver:

- Armchair exercise

- Tai Chi both seated and standing

- Circuit Training

- In house gym

- Balance, strength and coordination exercises

- Indoor and outdoor mobility

is offered in many hospice settings. What makes our service different is where our therapy can be delivered. It may be bold to say our service is totally unique but we are certain there is nothing equivalent in our immediate region.
The benefits are clear, regardless of the patient's changing condition we strive to maintain continuity making sure the individual is at the heart of everything we do; patients report after their exercise sessions they feel energised and it has given them the boost they need to carry on.

\section{P-109 CREATING A GROUP EXERCISE PROGRAMME TO SUIT THE VARIETY NEEDS OF ALL HOSPICE PATIENTS}

Nicola Silk, Patricia McGovern. Douglas Macmillan Hospice, Stoke on Trent, UK

\subsection{6/bmjspcare-2016-001245.132}

Aim To provide a group exercise programme to suit the variety of needs of all hospice In-patients, day therapy patients and community patients to enable them to exercise together as a group.

Background A group exercise session not only has physical benefits for patients, the social aspect of exercising together is extremely beneficial for patients in a hospice setting (Talbot Rice et al., 2014). Taking into account physical ability, medical conditions, needs and limitations of each individual person makes providing a group exercise a challenge.

Method Two hospice staff members trained as Tripudio Movement Instructors. The programme combines gentle stretching and strengthening in an aerobic exercise programme. It can be adapted to suit the individual needs of all patients, is done seated or standing and at any intensity level dependent on the individuals fitness level, physical ability and condition. Most importantly the sessions are fun.

Results The table below demonstrates the results of a 6 week programme held for one hour a week for ladies aged between $36 y r$ and $83 y r s$ with lymphoedema.

Following the program's success, the classes were adapted further to suit all day therapy, community and in- patients.

Conclusion Tripudio is an effective group exercise programme which can be adapted to enable patients with a variety of life-limiting conditions, symptoms and physical abilities to exercise together in a group setting.

\begin{tabular}{|c|c|c|}
\hline Medical conditions & Patient reported benefits & Additional comments \\
\hline Cancer & Reduction in lymphoedema & \\
\hline Bone metastases & Reduced pain & \\
\hline Lipodema & Reduction of breathlessness & \\
\hline Osteoarthritis & Reduction in analgesia & \\
\hline Underactive thyroid & Improved strength & Sessions are relaxing \\
\hline Surgical procedures & Improved balance & $\begin{array}{l}\text { Sessions are extremely } \\
\text { enjoyable }\end{array}$ \\
\hline Chronic pain & Improved mood & $\begin{array}{l}\text { Good to meet others } \\
\text { with similar conditions }\end{array}$ \\
\hline Asthma & Improved psychological health & Great fun \\
\hline Hypertension & Increased muscle tone & \\
\hline Heart failure & Increased mobility & \\
\hline Fractured humerus & Increased confidence & \\
\hline \multicolumn{3}{|l|}{ Atrial fibrillation } \\
\hline \multicolumn{3}{|l|}{ Osteoporosis } \\
\hline \multicolumn{3}{|l|}{ Diabetes } \\
\hline \multicolumn{3}{|l|}{ Total hip replacement } \\
\hline COPD & & \\
\hline
\end{tabular}

